\title{
BANZEIROS DO RIO NEGRO E A ESCOLA RIBEIRINHA: as aulas de educação física no contexto da hinterlândia amazônica
}

\author{
Alexsander Luiz, Braga Santa Brigida \\ Evandro de Morais Ramos
}

\section{Resumo}

O presente artigo, realizado com apoio da Coordenação de Aperfeiçoamento de Pessoal de Nível Superior (CAPES), traz os primeiros achados de uma pesquisa desenvolvida em nível de mestrado. Esse estudo busca compreender como as práticas socioculturais das comunidades tradicionais ribeirinhas estão inseridas nos conteúdos programáticos do componente curricular educação física. O modelo que orientou o processo metodológico da investigação baseou-se na pesquisa de campo, a partir de um estudo de caso. A coleta e análise dos dados partiram da observação de aulas de educação física e de imagens coletadas no campo da pesquisa. A pesquisa de campo foi realizada em uma comunidade ribeirinha localizada às margens do igarapé Tarumã Mirim - Baixo Rio Negro, em Manaus / Amazonas. A partir dos primeiros achados da pesquisa de campo, pode-se considerar que as práticas socioculturais ribeirinhas estão presentes nos conteúdos das aulas de educação física, seja direta ou indiretamente. Assim, é necessário evidenciar essas práticas e esses saberes locais dos escolares ribeirinhos e, para isso, sugere-se a formação continuada para os professores e a construção de um currículo que valorize o ser ribeirinho, bem como suas práticas sociais e culturais.

Palavras-chave: educação ribeirinha; educação física; práticas socioculturais; Amazônia.

\section{BANZEIROS OF RIVER BLACK AND THE RIVERSIDE SCHOOL: the physical education classes in the context of the amazon hinterland}

\section{Abstract}

This study was financed in part by the Coordenação de Aperfeiçoamento de Pessoal de Nível Superior (CAPES), presents the first results of a research developed at the master's level. This study seeks to understand how the socio-cultural practices of traditional riverside communities are included in the curriculum of the Physical Education curriculum component. The model that guided the methodological process of this research was based on field research as from a case study. The collection and analysis of the data came from observing the Physical Education classes and the images collected in the research field. The field research was carried out in a riverside community located on the banks of the Tarumã Mirim - Baixo Rio Negro stream, in Manaus / Amazonas. From the first findings of the field research, it can be considered that the riverside socio-cultural practices are present in the contents of Physical Education classes, either directly or indirectly. Thus, it is necessary to highlight these practices and local knowledge of riverside schoolchildren and, for that, it is suggested the continuing education for teachers the construction of curriculum that values riverside people, as well their social and cultural practices.

Keywords: riverside education; physical education; socio-cultural practices; Amazon.

\section{BANZEIROS DE RIO NEGRO Y LA ESCUELA RIBEIRINHA: las clases de educación física en contexto de la hinterlândia amazónica}

Resumen

Este trabajo se realizó con el apoyo de la Coordenação de Aperfeiçoamento de Pessoal de Nível Superior (CAPES) y presenta los primeros hallazgos de una investigación desarrollada a nivel de maestría. Este estudio busca comprender cómo las prácticas socioculturales de las comunidades ribereñas tradicionales se 
insertan en el programa de estudios del componente curricular de educación física. El modelo que orientó el proceso metodológico de esta investigación se basó en la investigación de campo por medio de un estudio de caso. La recopilación y el análisis de los datos comenzaron a partir de la observación en las clases de educación física y en las imágenes recopiladas en el campo de investigación. La investigación de campo se llevó a cabo en una comunidad ribereña ubicada a orillas del arroyo Tarumã Mirim - Baixo Río Negro, en Manaus / Amazonas. A partir de los primeros hallazgos de la investigación de campo, podemos considerar que las prácticas socioculturales ribereñas están presentes en los contenidos de las clases de educación física, sea directa o indirectamente. Por lo tanto, es necesario resaltar estas prácticas y el conocimiento local de los estudiantes ribereños y, para eso, se sugiere la capacitación continua para los maestros y la construcción de un plan de estudios que valore a las personas ribereñas, así como sus prácticas sociales y culturales.

Palabras clave: educación ribereña; educación física; prácticas sociales; Amazonía.

\section{INTRODUÇÃO}

O que se pensa sobre Amazônia? Florestas, rios, animais, índios... Esse questionamento lembra a primeira aula no curso de Pós-graduação em Sociedade e Cultura na Amazônia, em que um dos autores do texto é discente. As respostas iniciais sobre a Amazônia e seus significados, os debates, leituras, construções e desconstruções sobre o ser amazônico, o meio cultural, social, econômico, educacional e político que perduram nessa região, junto à sua vasta riqueza sociocultural, fazem refletir em relação às inúmeras traduções sobre o que é a Amazônia e a sua representatividade.

Ao abordar a Amazônia, variam-se os temas do campo do conhecimento científico que podem ser estudados nessa região. Pinto $(2005$, p. 99) analisa que há um novo senso comum sustentado pelas noções de meio ambiente, desenvolvimento sustentável, sociodiversidade, populações ribeirinhas, povos da floresta etc. Ao analisar os escritos produzidos sobre as temáticas supracitadas, observa-se que a maioria delas sugere conteúdos conservadores e romantizados sobre a região, não abordando a realidade da comunidade, principalmente os da hinterlândia amazônica ${ }^{1}$, que sofrem com descaso social, educacional, econômico e político.

Para abordar uma parte do aspecto educacional da região, o presente artigo enfoca as aulas de educação física, relacionando-as com as práticas socioculturais locais dos povos que vivem às margens dos rios e / ou florestas, bem como das várzeas interioranas da Amazônia, também conhecidos como povos tradicionais ribeirinhos ${ }^{2}$. Assim, o objetivo desse estudo visa compreender, a partir dos primeiros achados do campo da pesquisa, como essas práticas socioculturais locais se relacionam com os conteúdos da disciplina educação física em um locus ribeirinho. Percebe-se que a educação ribeirinha também pode se tornar uma forma de expressão intelectual que produz um pensamento social acerca das interpretações sobre Amazônia, visto que possuem particularidades e peculiaridades daqueles que dela usufruem. Com isso, criam-se várias interpretações sobre o ser amazônida, o ser ribeirinho, além das diversidades culturais, sociais, econômicas e históricas e, nas aulas de educação física, podem-se construir e reconstruir

\footnotetext{
${ }^{1}$ Hinterlândia Amazônica é a região considerada mais afastada dos centros urbanos, os interiores.

2 De acordo com Witkoski (2010, p. 27) índios, seringueiros, quilombolas, caboclos, ribeirinhos, caboclo-ribeirinhos (sociologicamente, camponeses amazônicos), são considerados "povos tradicionais", que possuem vasta experiência na utilização e conservação da biodiversidade e da ecologia dos ambientes de terras, florestas e águas, onde trabalham e vivem. Têm seus direitos garantidos pelo Decreto n. 8.750, de 9 de maio de 2016, que institui o Conselho Nacional dos Povos e Comunidades Tradicionais, e o Decreto n. 6.040, de 7 de fevereiro de 2007, que institui a Política Nacional de Desenvolvimento Sustentável dos Povos e das Comunidades Tradicionais.
} 
os significados do ser ribeirinho, relacionando-os às práticas sociais que norteiam esses ribeirinhos.

Essa pesquisa se configura como pesquisa de campo, de cunho observação participante, na qual se observaram as aulas de educação física em uma escola localizada na zona rural ribeirinha de Manaus, às margens do Rio Negro, e seus dados foram coletados pela observação e registros fotográficos de aulas de educação física. O artigo está dividido em três partes relevantes. $\mathrm{Na}$ primeira, é apresentada uma abordagem sobre a educação ribeirinha no contexto da hinterlândia Amazônica; na segunda, detalha-se o objeto de estudo e a discussão de seu objetivo, que se refere às aulas de educação física na escola ribeirinha; e, por fim, na terceira parte, são apresentadas as considerações finais.

\section{EDUCAÇÃO RIBEIRINHA NA HINTERLÂNDIA AMAZÔNICA}

$\mathrm{Na}$ abordagem sobre a educação ribeirinha, é necessário evidenciar que quem usufrui dela, por direito, é o ribeirinho. Mas quem é o ribeirinho? Ribeirinho é contextualizado a partir da denominação dos povos tradicionais, que pode ser o índio, seringueiro, quilombola, caboclo, que vive às margens dos rios, povoados ou comunidades nas áreas de várzea. Abreu, Oliveira e Silva (2013, p. 10) definem as populações ribeirinhas como:

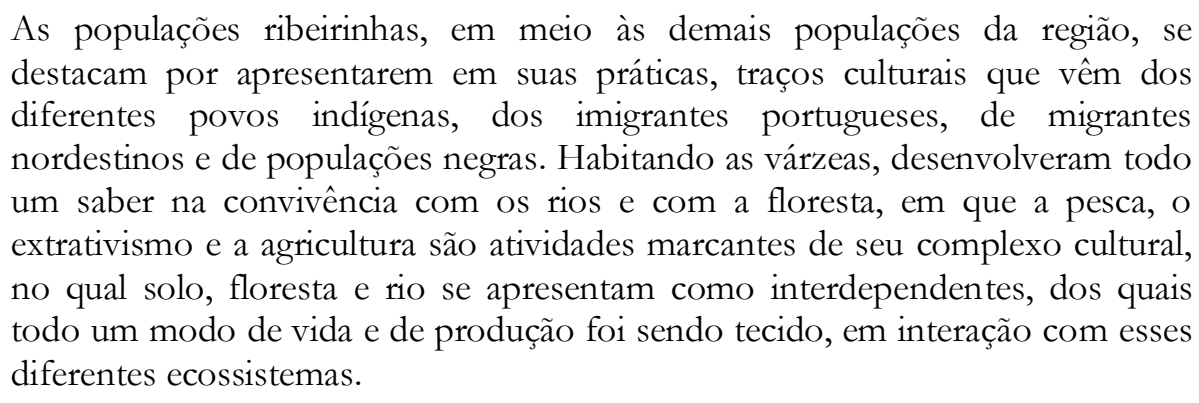

Os rios ou áreas de várzea, para o ser da Amazônia, refletem-se em diferentes significados ou figurações como explica Matos (2015, p. 65): “[...] o rio não só possibilita a alimentação, mas também sustenta e amplia suas figurações" enquanto ser amazônico, como porta de saída e entrada, assim como a diversidade de saberes que remete, a uma comunidade ribeirinha, as lendas urbanas, questões de sobrevivência durante os banzeiros. Ainda há a importância sociocultural que o rio remete ao ser ribeirinho, que faz parte da vida e da rotina dos moradores de áreas de várzea.

Os ribeirinhos possuem uma gama de conhecimentos socioculturais que se relacionam diretamente com a natureza, seja na riqueza de palavras que compõem seu vocabulário, suas práticas corporais, seu saber tradicional em relação a questões de saúde e medicamentos, as diferentes formas de cultivo, de manipulação de alimentos, entre outros.

Quando a pesquisa remete à educação do ribeirinho, evidencia-se um contexto histórico social diferente de outras realidades, principalmente no contexto da região amazônica, marcada por uma riqueza geográfica, social e plural e multicultural, com características próprias e totalmente diferentes das demais localidades brasileiras. Assim, Gonçalves (2005, p. 8) diz que:

Para os de fora, a imagem que se tem da Amazônia é a mais homogênea [...]. Para os habitantes da própria região, a "Amazônia" é um termo vago que adquire múltiplos significados correspondentes aos mais diferentes contextos sócio-ecológico-culturais específicos que são os espaços dos seus cotidianos. 
Assim, enquanto pra uns - os de fora, a "Amazônia" aparece no singular, para outros, isto é, para os que nela moram - ela é plural e multifacetada.

Essa diversidade do ser amazônico está intrinsecamente ligada ao contexto educacional que necessita, em seus currículos, abordar a riqueza cultural, social e plural, principalmente na educação ribeirinha, que está relacionada ao contexto dos rios, florestas e solos. Almeida (2016, p. 133-134) discute que, na realidade local dos ribeirinhos, os saberes são diversos e norteiam suas relações sociais, variando as relações culturais, religiosas e econômicas e estando relacionadas com as águas e florestas, perpetuando esse saber para leituras do mundo, ao interpretar a natureza, diferindo da lógica do conhecimento científico, indo ao encontro de suas experiências, trocas e convívio com os rios e a mata.

A necessidade de um currículo ribeirinho é de extrema importância e urgência, já que as práticas pedagógicas que se aplicam a uma realidade urbana, nem sempre são adequadas à realidade ribeirinha, pois o currículo urbano não atende às necessidades de quem mora em uma comunidade rodeada por rios. As culturas, costumes e práticas socioculturais são diferenciadas, e encontram-se em realidades opostas.

A Lei de Diretrizes e Bases da Educação Nacional (LDB, 1996) dá suporte para os municípios criarem seus currículos de acordo com sua realidade, principalmente em escolares do campo, que é o caso da educação ribeirinha. No entanto, não há um estudo publicado pelas secretarias de educação municipal e/ou estadual da região norte que definam um currículo para as escolas ribeirinhas e rurais, muitas apresentam apenas um currículo que deve ser seguido em escolas urbanas e rurais.

No contexto da educação ribeirinha amazônica, alguns avanços foram alcançados, como exemplo, o ajuste do calendário escolar diferenciado, de acordo com a realidade amazônica, que se relaciona ao ciclo das águas e aos períodos de enchente e vazante dos rios. No entanto, um ponto primordial ainda não está na realidade da educação ribeirinha amazônica: um currículo que aborde suas práticas socioculturais, realidades locais das comunidades e povos tradicionais ribeirinhos. Matos e Rocha Ferreira (2019, p. 376-377) explicam detalhadamente a necessidade de alteração do calendário escolar das escolas ribeirinhas pelas realidades naturais amazônicas e o respeito por esse aspecto social-natural-cultural. Assim:

[...] as peculiaridades climáticas do Amazonas fizeram reconhecer a necessidade de ajustes no calendário para melhor conduzir a educação escolarizada dos ribeirinhos. A realidade mostra escolas situadas em áreas de várzeas e de terra firme. Nos ciclos das águas, no período da vazante, alguns rios, lagos e igarapés são de difícil navegação, comprometendo a acessibilidade à escola e fazendo aumentar a distância e o tempo. No período de enchente, se a escola for situada em área de várzea e sua estrutura não for elevada, sua estrutura vai ficando progressivamente submersa, até que não se consiga mais ministrar aula. Por outro lado, na subida das águas, o rio ganha melhor navegabilidade: a água avança sobre terras e deixa-as submersas, permitindo atalhos, o que diminui as distâncias e o tempo de chegada à escola. $\mathrm{Na}$ expressão local, o rio no Amazonas, na subida das águas, torna-se "mar de água doce".

Quando se abordam as disciplinas escolares, não há um currículo diversificado para as peculiaridades da região amazônica nessa realidade da educação ribeirinha, que tome em conta suas práticas socioculturais, realidades locais das comunidades e de povos tradicionais ribeirinhos. Matos (2013, p. 116) afirma que: 
No universo amazônico, a vida se mantém, bem ou mal, graças às práticas socioculturais desenvolvidas ante os estímulos ambientais e as relações de interdependência. Apesar do processo de integração em curso, essas práticas resistem, provocam e renovam emoções. Caracterizadas de utilitárias, merecem atenção pelos valores morais, éticos e educacionais constituídos historicamente, fortalecendo o apego afetivo, a identidade ao lugar de origem e os hábitos do amazônida. Elas, guardadas as proporções, podem contribuir para as discussões sobre práticas autossustentáveis e gerar reflexões socioambientais.

As disciplinas escolares, na práxis pedagógica, quando agregam as práticas socioculturais locais, fortalecem a identidade amazônica e revelam a pluralidade da cultura brasileira, juntamente às manifestações da cultura do cotidiano dos ribeirinhos. Dessa forma, numa reflexão acerca de cultura, observa-se que o povo ribeirinho possui suas peculiaridades, singularidades e características próprias, que devem ser evidenciadas no cotidiano escolar.

De acordo com Abreu, Oliveira e Silva (2013, p. 14) "[...] o educador ribeirinho possui em seu entorno uma grande diversidade de elementos naturais que são ricos em conhecimentos e que podem contribuir na sua prática de sala de aula, bem como a própria vivência local: costumes, hábitos, entre outros". Assim, a práxis educativa na escola ribeirinha é ultrapassar os conteúdos de português, matemática, história, geografia e demais disciplinas; é vivenciar as práticas socioculturais existentes na região e explorá-las, aproximando o aluno à sua realidade, sabendo que aquele conteúdo também é uma forma de conhecimento e necessita ter visibilidade.

A educação ribeirinha, hoje, tem maior visibilidade no cenário local, já se discute sua importância e a necessidade de sua resistência. No entanto, ainda faltam vários pontos para uma educação de qualidade e plena para todos aqueles que dela necessitam. Uma realidade que ainda permanece nas escolas ribeirinhas é a das turmas multisseriadas. Essas turmas se alongam por muito tempo, fomentando a precarização da educação, tanto para os alunos, ao dividirem o espaço de sala de aula com crianças / adolescentes de diversas idades / séries, quanto para o professor, por ter de reformular diferentes planos de aulas, atividades extraclasse e avaliações. Essa realidade precisa ser superada e acrescida de turmas regulares, conforme a série e a faixa etária.

Em questão de formação, atualmente, observam-se vários professores com ensino superior lecionando nessa modalidade de educação básica, no entanto, é muito precária a formação continuada desse educador, desde atualizações curriculares a cursos de pós-graduação.

\section{ENCONTRO DOS RIOS: A EDUCAÇÃO RIBEIRINHA EM MANAUS}

$\mathrm{Na}$ esfera municipal de Manaus, a Secretaria Municipal de Educação (SEMED) é responsável pela pasta da educação; atualmente, a rede possui em torno de 491 escolas, divididas geograficamente por zonas distritais, que são: Sul, Centro-Sul, Oeste, Centro-Oeste, Norte I, Norte II, Leste I, Leste II e Rural. O objeto de estudo dessa pesquisa está localizado na zona rural de Manaus, que é dividida em rural rodoviária e rural ribeirinha. A zona distrital rural da SEMED possui 89 escolas, sendo 36 rodoviárias e 53 ribeirinhas, que se subdividem em 22 escolas no rio Amazonas e 31 no rio Negro.

A SEMED tem um grupo de trabalho em educação do campo, responsável pela elaboração, organização e acompanhamento das políticas públicas educacionais direcionadas às escolas situadas na área rural. O município de Manaus tem, ainda, um Comitê de Educação do Campo, criado em 2015, que tem por finalidade realizar fóruns municipais, promover debates e formações nas escolas do campo para elaboração da diretriz pedagógica (SEMED, 2018). 
Embora haja um grupo de trabalho - Comitê de Educação do Campo e uma zona distrital especificamente para atender as escolas rurais de Manaus - ainda não se tem uma diretriz curricular que norteie essas escolas. Atualmente, a Secretaria conta com uma diretriz geral, a partir da qual as escolas rurais devem adequá-la à sua realidade. Essa é uma das grandes dificuldades do componente curricular educação física, em que o currículo e seus conteúdos estão voltados totalmente para um locus que não condiz com a realidade local ribeirinha.

\section{O locus da pesquisa de campo}

O locus da pesquisa de campo está situado na zona rural ribeirinha de Manaus / Amazonas, na Comunidade Agrovila Amazonino Mendes, localizada às margens do igarapé Tarumã Mirim - Baixo Rio Negro. Essa comunidade pertence à reserva de desenvolvimento sustentável do Tupé.

Figura 1: Mapa da localização geográfica da área do estudo

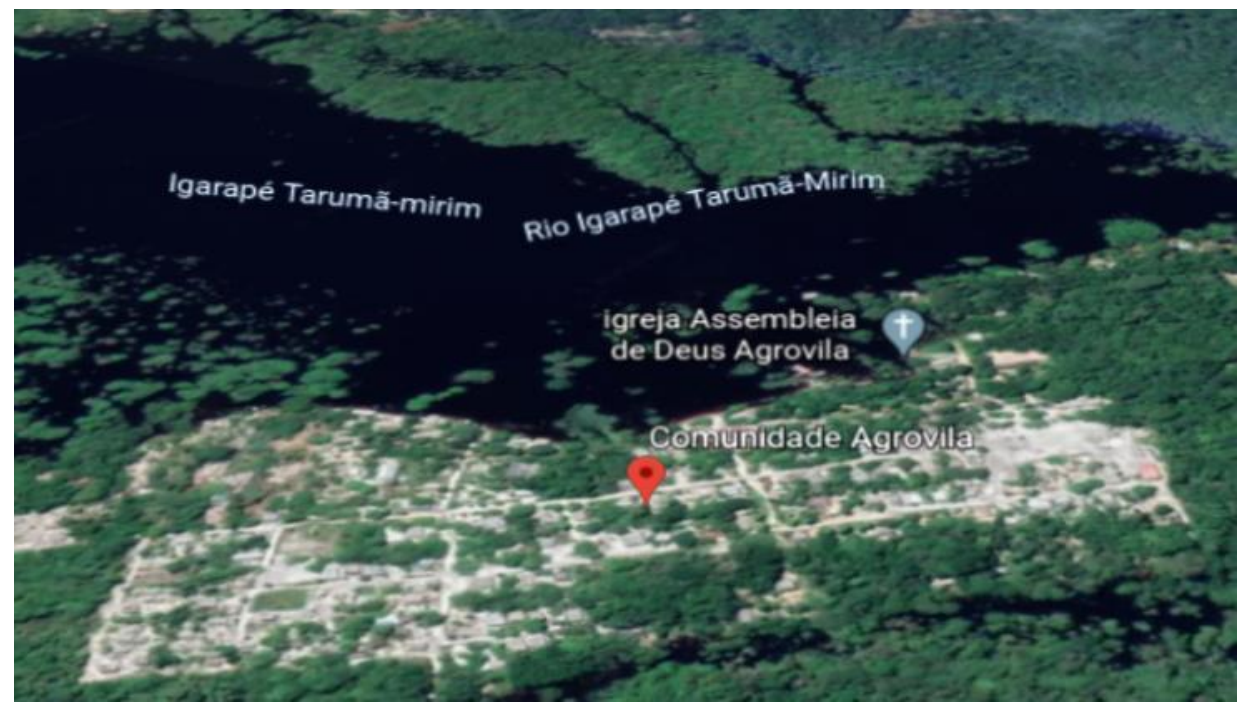

Fonte: Imagem de Satélite (Landsat) do Google Earth, em 20 jan. 2020.

O principal acesso à Comunidade se dá por meio de via fluvial, com tempo estimado de $1 \mathrm{~h} 25 \mathrm{~min}$ de viagem para chegar à zona urbana de Manaus. No entanto, nos tempos de seca e vazante do rio, o acesso à Comunidade pode demorar até $4 \mathrm{~h}$.

A Comunidade Agrovila Amazonino Mendes foi fundada em 10 de abril de 1994 e, de acordo com as estimativas do presidente da associação de moradores, moram na Agrovila aproximadamente 200 famílias e em torno de 500 habitantes. Na Comunidade existem cinco congregações religiosas (uma igreja católica, duas igrejas evangélicas, um terreiro de umbanda e uma igreja presbiteriana), e também possui estabelecimentos comerciais (mercearias) e uma Unidade de Apoio à Estratégia Saúde da Família, que funciona apenas às quartas-feiras com atendimentos consecutivos de médicos, enfermeiros e dentistas. Há energia elétrica na Comunidade, desde 2008, o que aconteceu por meio do Programa Luz Para Todos, criado no Governo Lula; no entanto, não conta com coleta de água, esgoto e lixo, que muitas vezes é queimado pelos próprios moradores. $\mathrm{Na}$ Agrovila tem uma escola, denominada Escola Municipal Paulo Freire, que atende os educandos da Comunidade e de comunidades vizinhas em que não há escolas. 
Figura 2: Entrada da Comunidade Agrovila

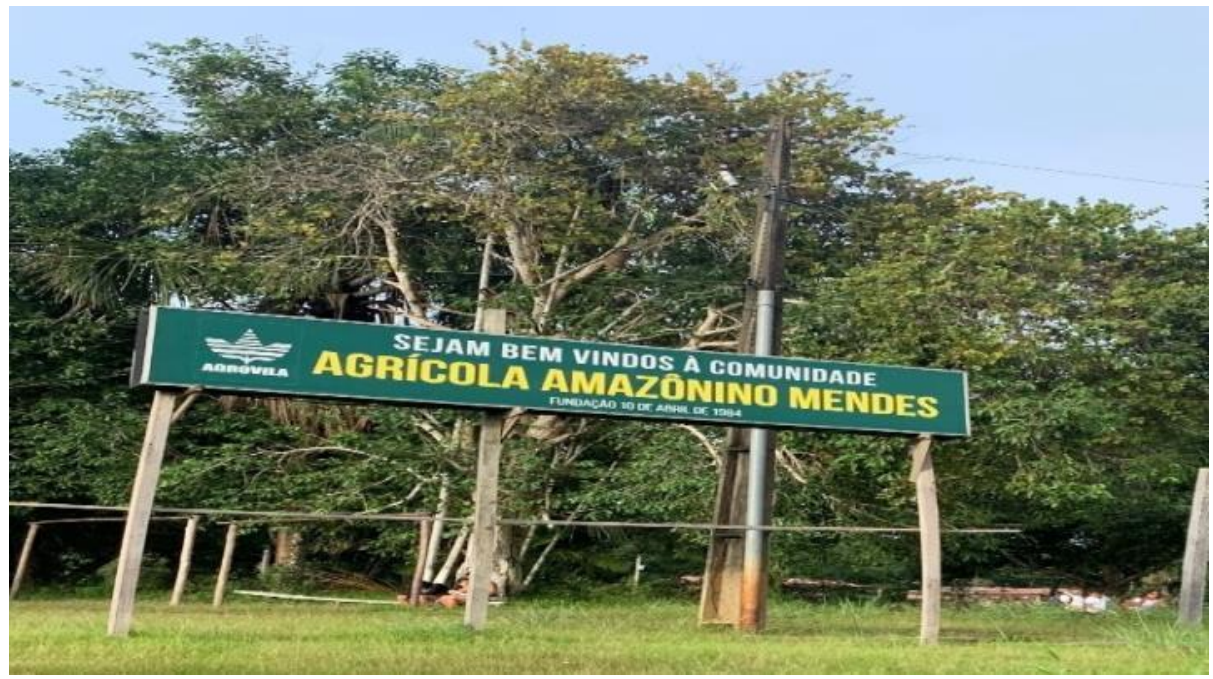

Fonte: Pesquisa de campo, jan. 2020.

Mesmo com a falta de políticas públicas básicas, a Comunidade Agrovila resiste e continua lutando por condições dignas de sobrevivência em diversos aspectos sociais, como segurança, saúde, educação de qualidade, comunicação (há somente uma operadora de serviço móvel que abrange a região e o único local que possui wi-fi é a escola).

\section{A Escola Ribeirinha Paulo Freire}

\section{Figura 3: Parte externa da Escola Municipal Paulo Freire}

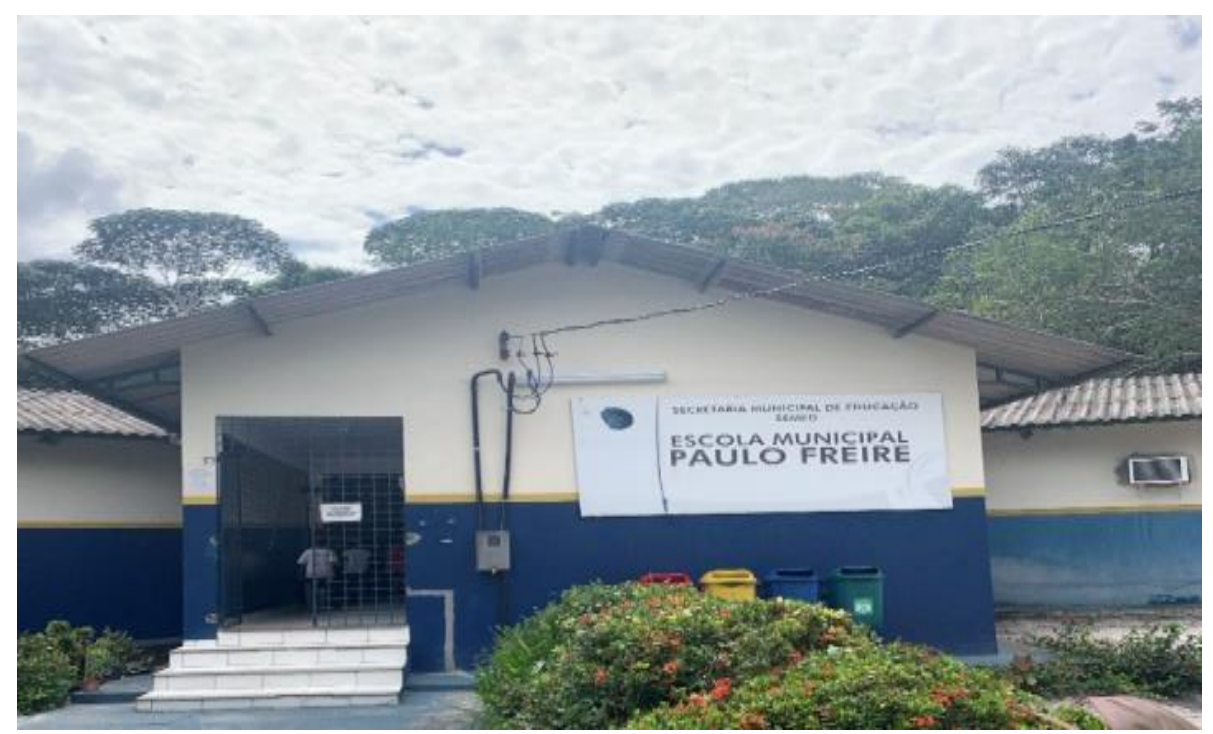

Fonte: Pesquisa de campo, jan. 2020.

A Escola Municipal Paulo Freire teve seu marco histórico em 1995, a partir do "Seu Hugo", que foi um dos primeiros moradores da Comunidade. Sr. Hugo tinha cinco filhos e reconhecia a necessidade de que eles estudassem. Como não tinha condições de levar todos os 
dias os filhos à zona urbana para frequentarem uma escola, construiu um barracão coberto de palha em seu próprio quintal, dando início à escolinha naquele local, onde sua esposa, Dona Guimarães, era a professora, lecionando para os cinco filhos e mais 15 crianças da Comunidade.

Em 1996, Sr. Hugo, como presidente da associação de moradores, conseguiu a parceria com a SEMED e a responsabilização do município para a construção da escola em um espaço adequado. Não demorou muito e foi preciso construir um espaço maior para as crianças. O Sr. Hugo escolheu uma área apropriada e a SEMED providenciou uma escola toda pré-moldada, com madeira bem trabalhada e envernizada e, em poucos dias, com a participação de toda a Comunidade, a escola foi montada. Com o término da montagem da nova escola, a SEMED providenciou uma professora formada no magistério para assumir a direção como gestora e professora concomitantemente. Assim, em junho de 1997, a escola foi entregue à Comunidade com o nome de Escola Municipal Paulo Freire (SEMED, 2019).

A Escola Municipal Paulo Freire funciona nos três turnos: matutino, vespertino e noturno, com turmas que vão desde a educação infantil ao ensino fundamental II, em classes multisseriadas, e com uma turma de educação de jovens e adultos (EJA) no turno noturno. Também há parceria com a Secretaria de Estado de Educação, que oferece, no turno noturno, o ensino médio, no mesmo espaço. A escola possui quatro salas de aulas, um refeitório, uma sala da direção e secretaria, dormitórios masculino e feminino para professores e cerca de 200 alunos em todas as modalidades de ensino.

As turmas de educação infantil e ensino fundamental I ( $1^{\circ}$ ao $5^{\circ}$ ano $)$ têm um professor titular em todo o ano letivo; já as turmas de ensino fundamental II $\left(6^{\circ}\right.$ ao $9^{\circ}$ ano $)$ funcionam de forma itinerante. Modelo itinerante é o ensino ofertado nas zonas rurais de Manaus, que funciona em blocos pedagógicos com duração de três, quatro ou seis meses; esses blocos pedagógicos podem ser trimestral, quadrimestral ou semestral, quando os professores ministram sua disciplina, que acontece somente durante o período de duração do bloco pedagógico, naquela escola. Os professores que ministram aulas nessa etapa de ensino são lotados em duas ou três escolas de determinada zona rural; no caso dos professores da Escola Paulo Freire, ficam em três escolas do rio Negro, e devem trabalhar todo o conteúdo do ano letivo nesse período de três meses.

Percebe-se que, com o modelo itinerante, há grande perda para alunos e professores, já que, muitas vezes, o trabalho pedagógico aumenta em dobro, para poder conseguir abordar o conteúdo do ano letivo em três meses; ainda, para os alunos, o desenho e a rapidez dessa organização de conteúdos acarreta a falta de um processo contínuo de ensino-aprendizagem que dure o ano todo. Nesse processo, a Secretaria de Educação se beneficia, uma vez que reduz o quadro de professores, além de não deixar professores fixos em cada escola.

\section{Aulas de educação física na Comunidade Agrovila}

A Escola Municipal Paulo Freire tem um professor titular que ministra a disciplina de educação física. Esse professor é itinerante e permanece na comunidade escolar durante um trimestre; no atual período letivo, a temporada acadêmica estava prevista para ser cursada de janeiro a abril de 2020. O docente ministra aulas nas turmas da educação infantil e do ensino fundamental I e II, lecionando em todas as turmas dessa escola municipal.

O profissional tem graduação em educação física e é especialista em educação física escolar. Há cinco anos é servidor público efetivo da Prefeitura Municipal de Manaus, na Secretaria Municipal de Educação, sendo lotado há dois anos na região ribeirinha do Rio Negro, na zona geográfica onde está localizada a Escola Paulo Freire.

$\mathrm{Na}$ escola ribeirinha Paulo Freire, a disciplina educação física ocupa quatro tempos de aula em cada turma do ensino fundamental II e dois tempos de aula nas turmas de educação 
infantil e ensino fundamental I. A carga horária nas turmas de ensino fundamental II é maior, devido ao fato de elas serem itinerantes e precisarem cumprir toda a carga horária em tempo reduzido.

$\mathrm{Na}$ rede municipal de Manaus, a educação física situa-se, na proposta curricular, na grande área de Linguagens, garantida nas grades curriculares do ensino fundamental I e II. Na educação infantil, não há obrigatoriedade de aulas de educação física, ocorrendo somente nas escolas em que o professor não tem turmas suficientes no ensino fundamental e completa as $40 \mathrm{~h}$ semanais assumindo algumas turmas de educação infantil e projetos esportivos no contraturno escolar.

As aulas de educação física na Escola Paulo Freire seguem a proposta pedagógica da SEMED que, por sua vez, é comum a todas as escolas de ensino fundamental I e II, sendo elas urbanas ou rurais. No entanto, essa proposta pouco se aproxima da realidade das escolas rurais, sejam elas escolas rodoviárias ou ribeirinhas. Há um grande distanciamento da realidade rural ribeirinha à prática dos conteúdos sugeridos na proposta, tornando sempre necessária a "adequação" desses conteúdos, pelo professor, às reais possibilidades da região, pois muitas vezes não há nem estrutura física e nem materiais pedagógicos necessários e adequados para atuar satisfatoriamente nessa realidade.

Ao iniciar a pesquisa de campo, foi analisado, por meio de observação participante, o modo como ocorria o processo teórico-prático-metodológico das aulas de educação física, acompanhando-se diariamente as aulas do professor que atuava em turmas de educação infantil e de ensino fundamental I e II. Além disso, observou-se, também, se o objetivo da disciplina estava sendo cumprido, da mesma forma que se observou se as práticas locais socioculturais estavam inseridas nas aulas do componente curricular.

Para contribuir no estudo desse objeto de investigação, é necessário descrever a realidade dos espaços onde se realizam as aulas de educação física. A Comunidade Agrovila é cercada por floresta e águas do rio; o igarapé e suas praias são o cartão postal de entrada da Comunidade, além de ser o lazer de seus moradores. Sabendo-se que a escola não tem quadra e / ou ginásio esportivo para práticas corporais, o local das aulas passa a ser os espaços naturais da própria Comunidade, como: campos de futebol, gramado à beira do rio, o próprio rio, a floresta, e a sede comunitária - o único lugar coberto para a efetivação de práticas durante aulas de educação física. Apesar dos riscos naturais, o professor e seus alunos exploram esses espaços e atrelam práticas socioculturais locais, mesmo que involuntariamente.

Figura 4: Campo de futebol da comunidade e um dos locais das aulas práticas de educação física

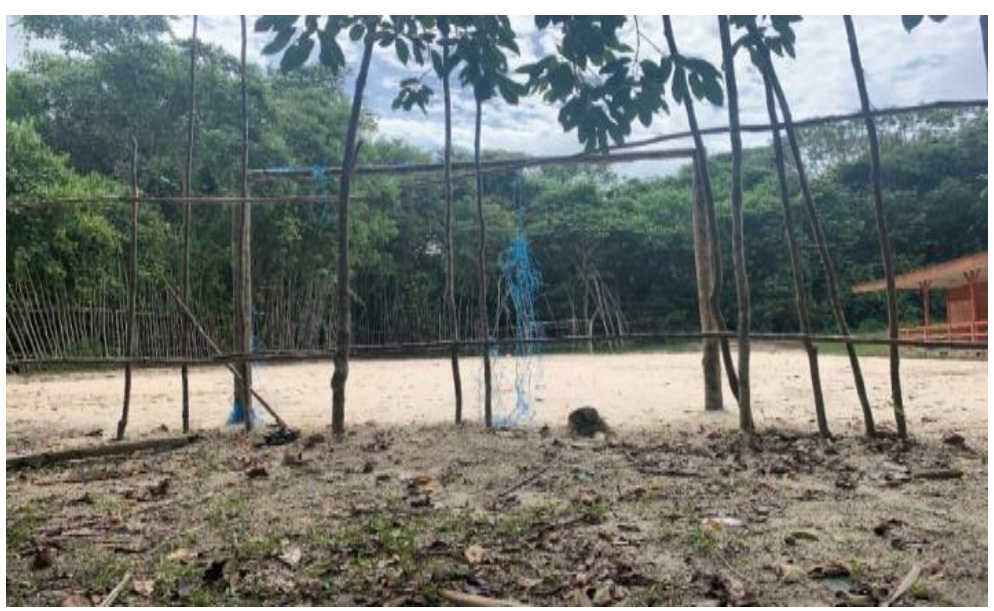

Fonte: Pesquisa de campo, jan. 2020. 
Figura 5: Sede da Comunidade Agrovila: único lugar coberto para as aulas práticas de educação física

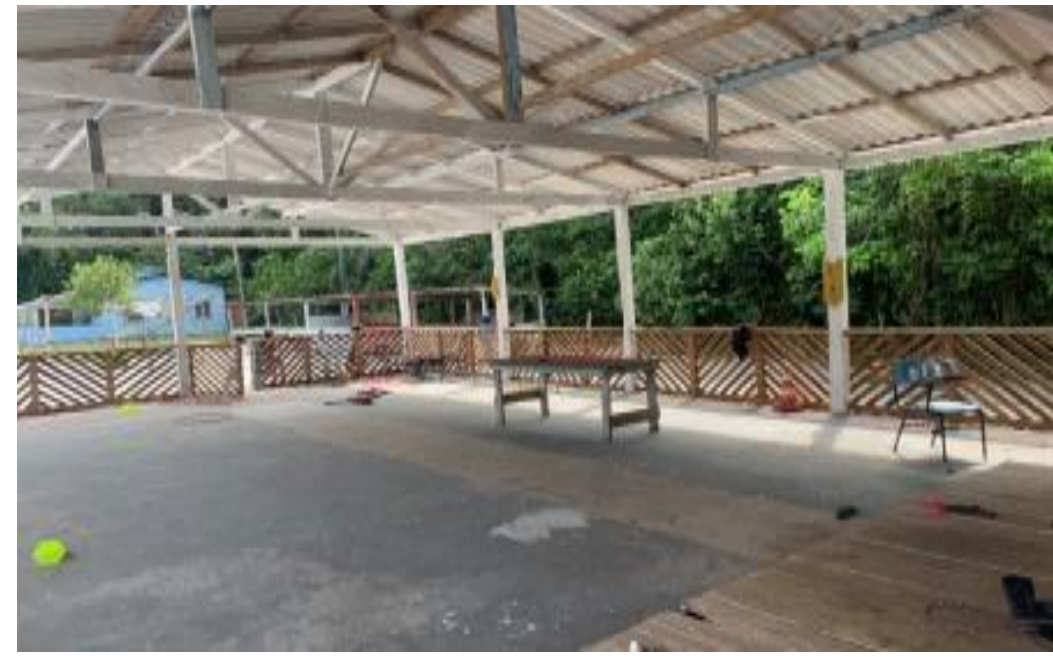

Fonte: Pesquisa de campo, jan. 2020.

Figura 6: Trave de futebol feita pelos moradores com madeiras da própria Comunidade

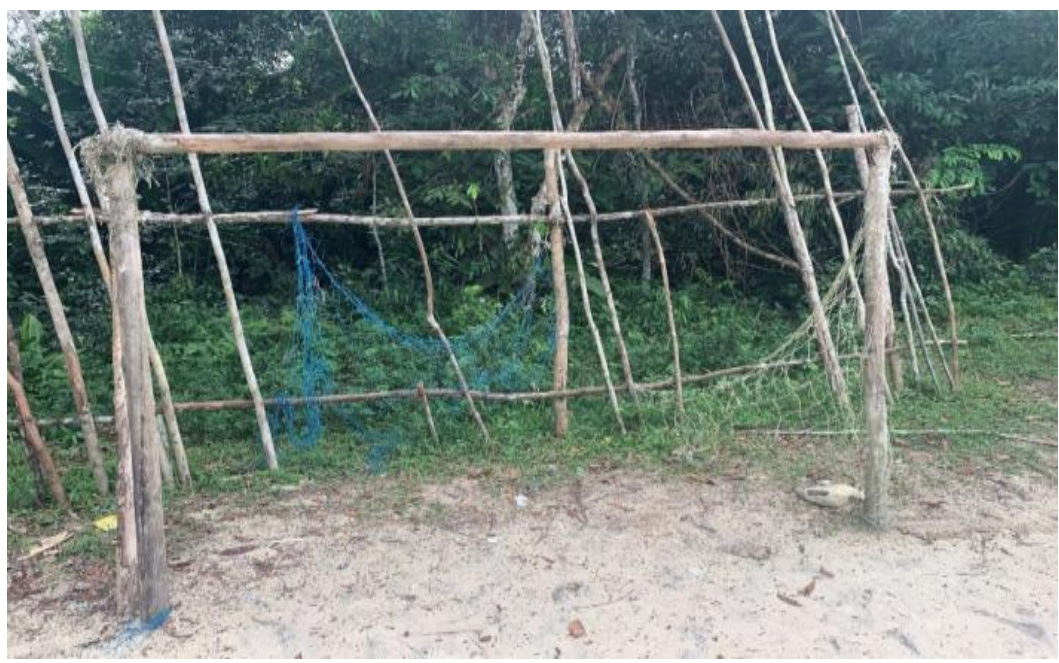

Fonte: Pesquisa de campo, jan. 2020.

Ao iniciar a observação das aulas de educação física na Comunidade Agrovila, os primeiros aspectos a serem apontados são: o quão a diversidade cultural está presente nessas aulas e a grande quantidade de práticas socioculturais locais ${ }^{3}$ que se entrelaçam aos conteúdos do componente curricular educação física.

Os conteúdos das aulas de educação física variam entre as turmas da educação infantil e ensino fundamental I e II: o professor verifica a proposta pedagógica do município e alia o conteúdo à realidade. Na proposta municipal da educação infantil, diretamente, a disciplina de educação física não é evidenciada, é tratada apenas como corpo, gestos e movimentos (SEMED,

\footnotetext{
${ }^{3}$ Quando se trata de práticas socioculturais locais, no decorrer desse escrito, evidenciam-se as características e modo de vida da região específica, que podem ser compreendidas como saberes populares, dialetos próprios da Amazônia, a fonte de trabalho daquela região, que varia entre a pesca, a caça, o plantio e o cultivo.
} 
2016) e, a partir desse referencial, o professor trabalha o desenvolvimento motor, coordenação motora grossa e fina, equilíbrio, jogos e brincadeiras, ou seja, atividades que trabalhem diretamente esses três itens abordados na proposta municipal. No ensino fundamental, há uma proposta sequencial de conteúdos que abarcam jogos, esportes, dança, lutas, ginástica etc. Assim, é necessário adaptar os conteúdos à realidade ribeirinha, abordando como podem ser tratados em ambientes naturais.

O profissional de educação física não atua sobre o corpo ou com movimento em si, não trabalha com o esporte em si, não lida com a ginástica em si. Ele trata do ser humano nas suas manifestações culturais relacionadas ao corpo e ao movimento humanos, historicamente definidos como jogo, esporte, dança, luta e ginástica. O que irá definir se uma ação corporal é digna de trato pedagógico pela educação física é a própria consideração e análise desta expressão na dinâmica cultural específica do contexto onde se realiza (DAOLIO, 2004, p. 9).

$\mathrm{Na}$ análise do contexto cultural da Comunidade Agrovila e atrelado aos espaços naturais que são o locus das aulas de educação física, os conteúdos do componente curricular ganham novas re(significações) e diversas formas de representação no espaço natural. Nas turmas de educação infantil, a partir do trato da coordenação motora grossa e fina, os saberes locais eram evidenciados, ainda que não fossem o objetivo principal da aula. Nas imagens a seguir, pode-se observar o banzeiro ${ }^{4}$, uma prática sociocultural ribeirinha, sendo trabalhado a partir da coordenação motora fina. Os alunos desenharam as ondas do banzeiro e, depois, pintaram com a cor que preferissem; no entanto, um aluno questionou que o banzeiro ficava de duas cores: da cor do rio (escuro) e branco. Com isso, pode-se observar o quão rico é o conhecimento cultural local dos alunos, que conhecem a realidade ribeirinha e agregam seus saberes ao processo de ensino-aprendizagem.

Figura 7: Banzeiros nas águas do rio Negro

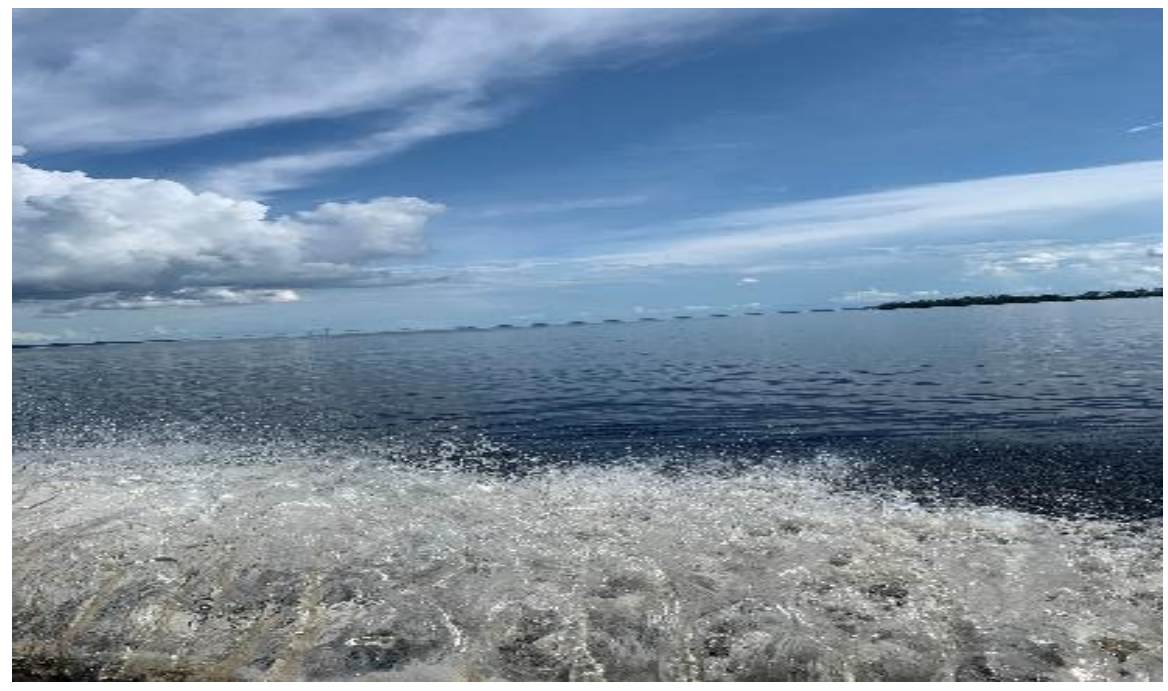

Fonte: Pesquisa de campo, jan. 2020.

\footnotetext{
$4 \mathrm{O}$ termo banzeiro na Amazônia remete às ondas que se formam nos rios devido ao movimento dos barcos, semelhantes às ondas do mar.
} 
Figura 8: Exemplificação do banzeiro na lousa feito pelo professor

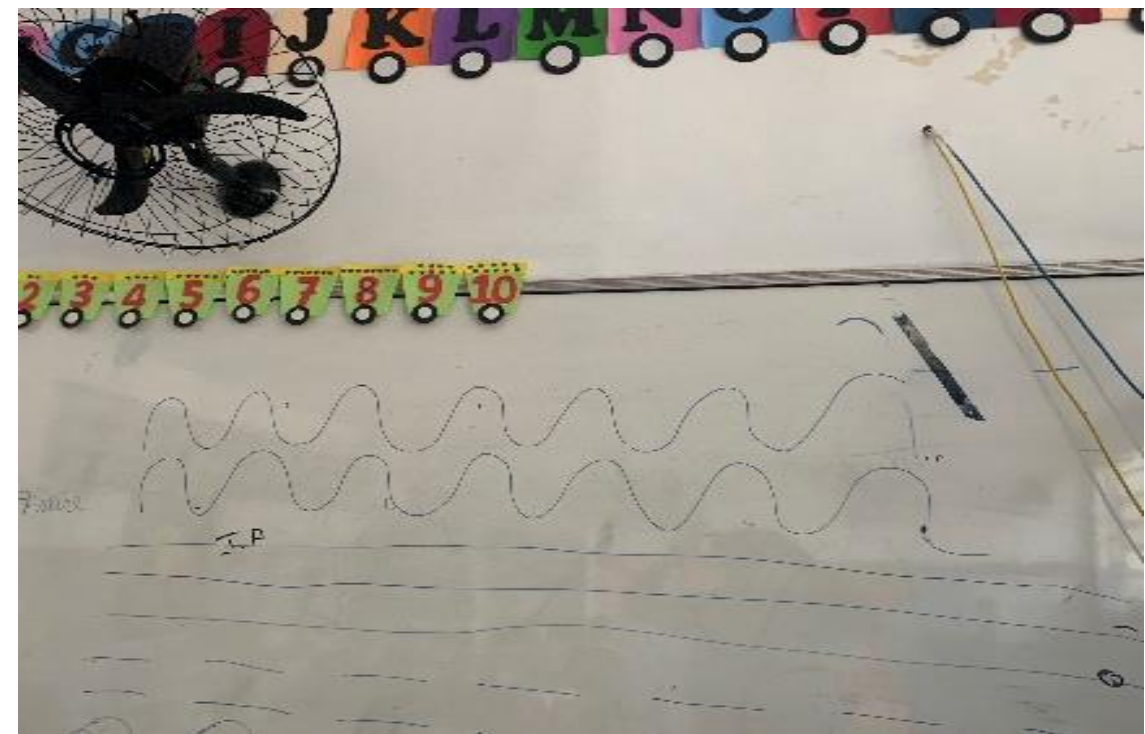

Fonte: Pesquisa de campo, jan. 2020.

Figura 9: Desenho de crianças da educação infantil sobre o seu banzeiro

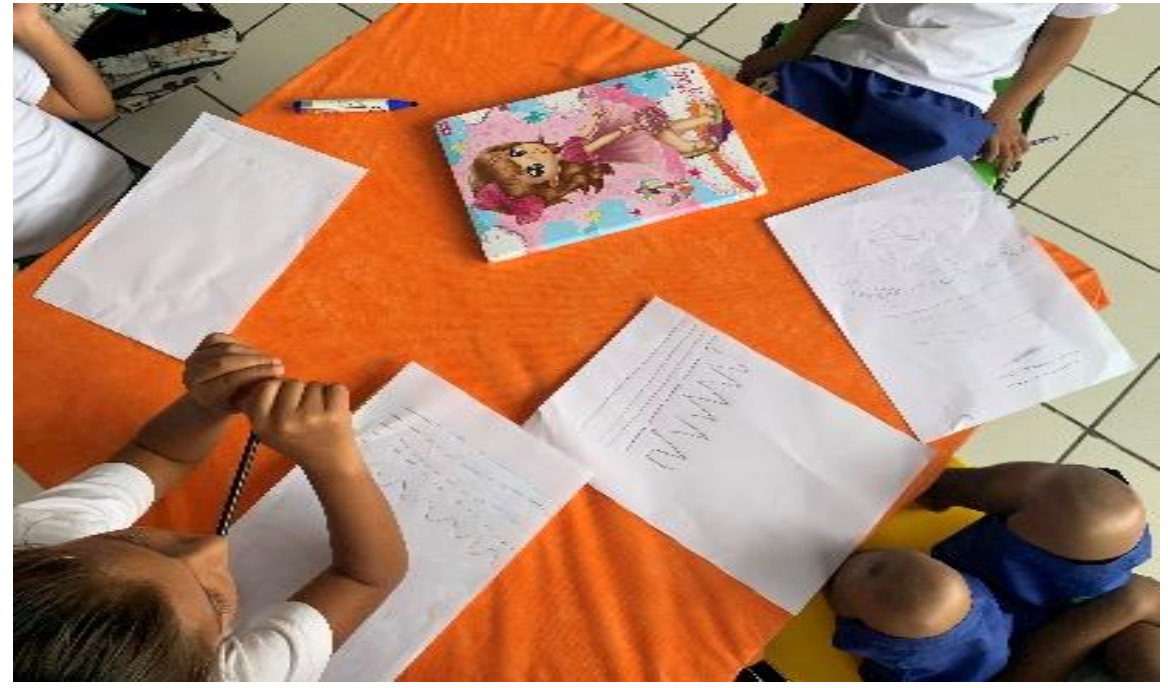

Fonte: Pesquisa de campo, jan. 2020.

Nas turmas de ensino fundamental, também se percebe o leque de conhecimentos locais e reprodução do contexto nas aulas de educação física. Atravessar pontes estreitas é rotina diária dos moradores da Comunidade Agrovila; essas pontes são denominadas, no linguajar popular ribeirinho, de "pinguela" e, para utilizá-la, é necessário concentração, agilidade, flexibilidade, noções de espaço-temporal e, principalmente, equilíbrio. Todas essas capacidades físico-motoras são trabalhadas no contexto da educação física escolar e, na Escola Paulo Freire, essas capacidades são exploradas de maneira diversificada, por meio da mureta da sede comunitária, denominada pelo professor e seus alunos de "pinguela da escola". 
Figura 10: Andando pela pinguela improvisada
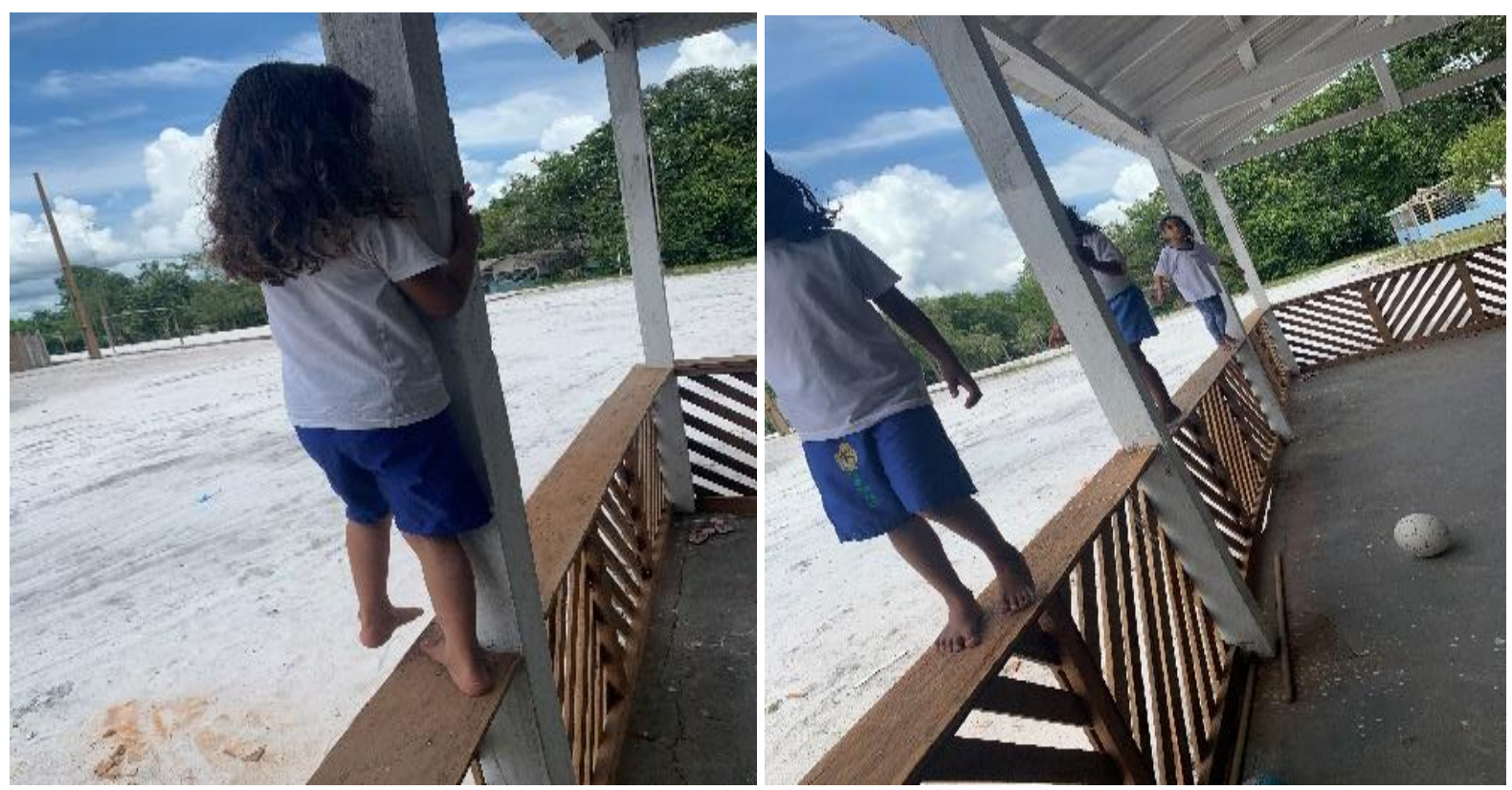

Fonte: Pesquisa de campo, jan. 2020.

Os jogos, bem como as brincadeiras, estão presentes e são bastante explorados nas aulas de educação física ribeirinha, principalmente, os simbólicos, que levam sentidos culturais e se aproximam da realidade dos educandos. As manjas, chicotinho queimado, paca e onça, são brincadeiras populares que fazem parte do cotidiano das crianças da Agrovila, e já que há um grande espaço natural disponível, a exploração do ambiente acontece em vários sentidos, desde os espaços longos para brincar, correr e pular, até a colheita de frutas das diversas árvores que rodeiam a Comunidade.

$\mathrm{Na}$ exploração da colheita, nas aulas de educação física são feitas competições a partir das experiências dos próprios alunos e, uma delas, era a de "tirar açaí do açaizeiro". Os alunos subiam na árvore de açaí e pegavam o máximo de frutos que conseguissem. Essa atividade aborda, pedagogicamente, competição, velocidade, reação e agilidade, todas capacidades físicas essenciais a serem desenvolvidas no processo de ensino-aprendizagem. Além disso, a prática traz uma realidade executada diariamente por muitos, seja como forma de sobrevivência para ajudar financeiramente em casa, seja para ajudar os pais a retirarem os frutos, ou, ainda, em momentos de diversão e brincadeiras. 
Figura 11: Competição do “apanhar” o açaí mais rápido
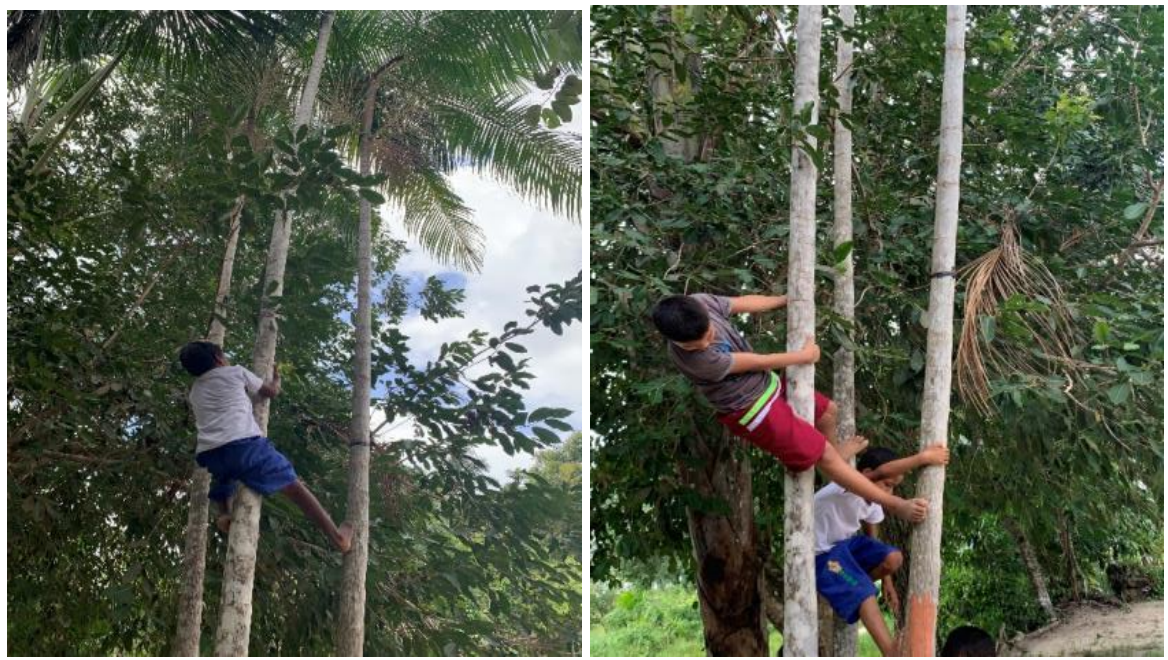

Fonte: Pesquisa de campo, jan. 2020.

Os rios e a floresta também fazem parte do contexto das aulas de educação física, no entanto, ainda há receio, por parte do professor e da gestão escolar, quanto ao uso desses espaços naturais, uma vez que há risco de acidentes. Ainda assim, é necessário que o aluno tenha contato com tais ambientes, pois o rio e a floresta fazem parte da vida de cada aluno da escola ribeirinha — todos são familiarizados com esses espaços naturais.

No decorrer das primeiras semanas da pesquisa de campo, apenas uma atividade foi feita às margens do igarapé: uma atividade recreativa em que nem todos puderam participar, pois os pais não autorizaram, participando apenas da caminhada ecológica. Nessa atividade, pela floresta até a beira do rio, observaram-se os saberes que os alunos têm acerca da proteção, seja em relação a animais selvagens, a plantas venenosas e a questões próprias de sobrevivência - naquele momento, invertiam-se os papéis: o professor começava a receber novos saberes dos alunos, que detinham o conhecimento.

Figura 12: Lazer à beira do rio

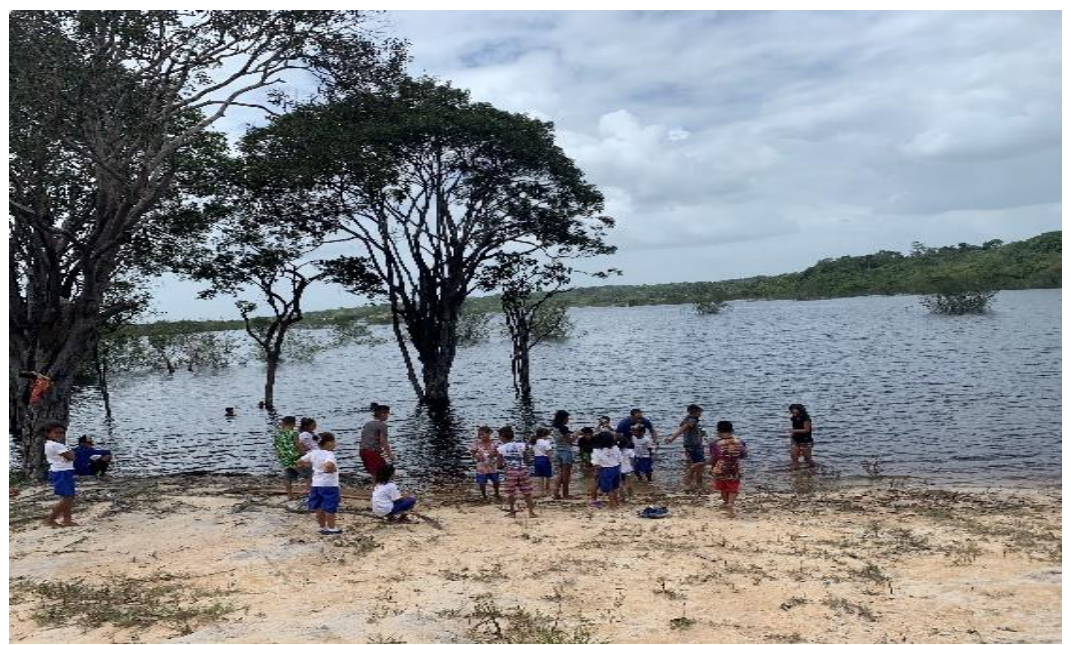

Fonte: Pesquisa de campo, jan. 2020. 
Figura 13: Caminhada na reserva florestal da comunidade

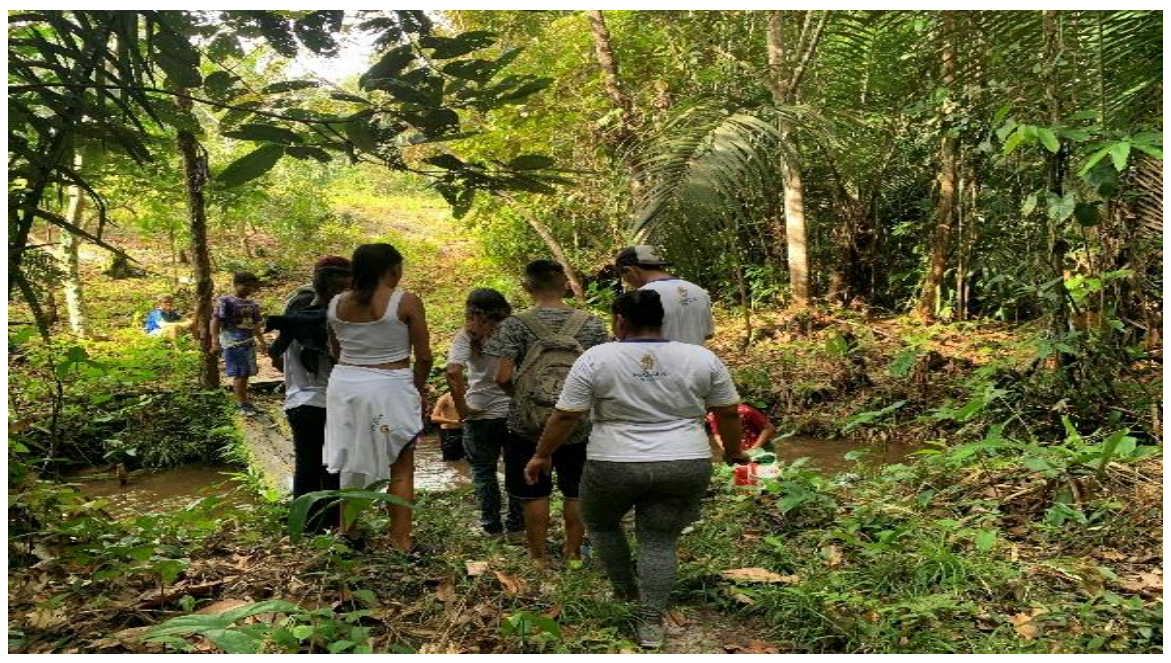

Fonte: Pesquisa de campo, jan. 2020.

A escola ribeirinha disponibiliza diversas opções de práticas corporais que variam em ambientes naturais, ricos em cultura local e práticas socioculturais. No entanto, é notória a necessidade de sequenciamento didático para o professor, principalmente no que se refere à formação para o ambiente ribeirinho, com meios de suprir uma boa estrutura física, a constante falta de materiais e condições dignas de trabalho, que diferenciam a zona urbana da rural.

\section{CONSIDERAÇÕES FINAIS}

A Amazônia é marcada por ampla diversidade de seus povos, das culturas, do meio ambiente e das diversas produções que a cercam. Desde que foi "inventada", como afirma Gondim (2007), sofre um processo de colonização e choque cultural do seu povo com aqueles que vieram a "descobri-la". Mas é necessário se questionar acerca do conhecimento em relação à Amazônia. Essa resposta é complexa e, antes de respondê-la, é também necessária uma reflexão. As respostas precisam ir além de floresta, rios, animais e índios. Amazônia é diversidade, é riqueza cultural, social, econômica, educacional; sendo assim, todos esses âmbitos devem estar interligados para o pleno desenvolvimento da região.

Ao refletir sobre o tema, diversos autores evidenciam a necessidade de se pensar a Amazônia em diversos contextos de forma crítica, social e cultural. Sendo assim, tratar a educação dos povos tradicionais ribeirinhos é uma excelente alternativa para dialogar cientificamente - a educação transforma vidas e por isso há que defendê-la em todo o território brasileiro.

$\mathrm{Na}$ abordagem das aulas de educação física, o ambiente natural das florestas e dos rios agrega um leque de possibilidades para sistematizar e (re)pensar práticas metodológicas que envolvem conteúdos desse componente curricular, que necessita ter presente as práticas socioculturais locais, mesmo indiretamente. Mesmo quando minimamente abordadas, as aulas de educação física devem ser mais exploradas e presentes no contexto escolar ribeirinho, pois dão visibilidade e representatividade aos conhecimentos socioculturais da localidade. 
Para a plena contextualização das práticas culturais ribeirinhas nas aulas de educação física, indica-se não apenas a diversificação metodológica por parte do professor, mas, sim, a definição de uma proposta curricular ribeirinha, que expresse os anseios do povo, valorizando os rios e as florestas. Com isso, os alunos estarão conscientes de que suas práticas são contextualizadas e vivenciadas na escola.

Por fim, conclui-se que a formação continuada para o professor dos rios é indispensável, e que essa seja relacionada à sua realidade, que envolva os conteúdos da educação física, jogos, dança, esporte, luta e ginástica, atrelados aos conhecimentos culturais e locais do povo, explorados nos ambientes naturais; somente assim ter-se-á mudança qualitativa e transformadora nas aulas de educação física no âmbito escolar ribeirinho.

\section{REFERÊNCIAS}

ABREU, Waldir Ferreira de; OLIVEIRA, Damião Bezerra; SILVA, Érbio dos Santos. Educação ribeirinha - saberes, vivências e formação no campo. Belém: GEPEIF- UFPA, 2013.

ALMEIDA, Edielso Manoel Mendes de. Ecologia de saberes: um estudo do diálogo entre o conhecimento escolar e o saber popular dos ribeirinhos da Ilha do Açaí. 225f. Tese, Doutorado em Educação, Universidade Nove de Julho, São Paulo, 2 dez. 2016.

BRASIL. Ministério da Educação. Lei n. 9.394 de 20 de dezembro de 1996. Lei de Diretrizes e Bases da Educação Nacional, 1996.

BRASIL. Decreto n. 6.040, de 7 de fevereiro de 2007. Institui a Política Nacional de Desenvolvimento Sustentável dos Povos e Comunidades Tradicionais. Diário Oficial da União. Brasília, Distrito Federal: Presidência da República, 2007.

BRASIL. Decreto n. 8.750, de 9 de maio de 2016. Institui o Conselho Nacional de Povos e Comunidades Tradicionais. Diário Oficial da União. Brasília, Distrito Federal: Presidência da República, 2016.

DAOLIO, Jocimar. Educação física e o conceito de cultura. Campinas: Autores Associados, 2004.

GONÇALVES, Carlos Walter Porto. Amazônia, Amazônias. São Paulo: Ed. Contexto, 2005.

GONDIM, Neide. A invenção da Amazônia. Manaus: Ed. Valer, 2007.

MATOS, Gláucio Campos Gomes de. Entre rios e florestas: experiências de campo de um professor de educação física em ambiente amazônico. Em Aberto, Brasília, v. 26, n. 89, p. 107-118, jan./jun. 2013.

MATOS, Gláucio Campos Gomes de. Ethos e figurações na Hinterlândia Amazônica. Manaus: Ed. Valer: FAPEAM, 2015.

MATOS, Gláucio Campos Gomes de; ROCHA FERREIRA, Maria Beatriz. Educação em comunidades amazônicas. Revista de Educação PUC-Campinas, [s. 1.], v. 24, n. 3, p. 367-383, out. 2019.

PINTO, Renan Freitas. A viagem das ideias. Estudos Avançados, v. 19, n. 53, p. 97-114, 1 abr. 2005.

PREFEITURA DE MANAUS, Secretaria Municipal de Educação. Educação do Campo, das Águas e Florestas, 2018. Disponível em: http://semed.manaus.am.gov.br/educacao-do-campo/. Acesso em: 12 mar. 2020.

PREFEITURA DE MANAUS, Secretaria Municipal de Educação. Projeto Político Pedagógico Escola Municipal Paulo Freire. Manaus: Semed Manaus, 59 p., 2019. 
WITKOSKI, Antonio Carlos. Terras, florestas e águas de trabalho: os camponeses amazônicos e as formas de uso de seus recursos naturais. 2. ed. São Paulo: Annablume Ed., 2010.

Submetido em janeiro de 2020. Aprovado em março de 2020.

\section{Informações dos autores}

Alexsander Luiz Braga Santa Brigida

Mestrando no Programa de Pós-Graduação Sociedade e Cultura na Amazônia na Universidade Federal do Amazonas (UFAM); Professor da Secretaria de Educação e Desporto do Amazonas (SEDUC-AM).

E-mail: alexlbrigida@gmail.com

ORCID: https://orcid.org/0000-0002-6110-4773

Link Lattes: http://lattes.cnpq.br/4011847091198810

Evandro de Morais Ramos

Doutor em Tecnologias Educativas pela Universidade de Ilhas Baleares; Professor Associado na Universidade Federal do Amazonas (UFAM); Docente no Programa de Pós-Graduação Sociedade e Cultura na Amazônia (UFAM).

E-mail: evandromramos@hotmail.com

ORCID: https://orcid.org/0000-0002-5808-6375

Link Lattes: http://lattes.cnpq.br/0764449120814936 